\title{
CFD Analysis and Electrical Efficiency Improvement of a Hybrid PV/T Panel Cooled by Forced Air Circulation
}

\author{
${ }^{1} \mathrm{M}$. tech scholar \\ Truba Institute of Engineering \& Information Technology \\ ${ }^{2}$ Director \\ Truba Institute of Engineering \& Information Technology \\ ${ }^{3}$ Assistant professor \\ Truba Institute of Engineering \& Information Technology
}

${ }^{1}$ Alok Kumar Singh, ${ }^{2}$ Dr Rajeev Arya, ${ }^{3}$ Shravan Vishwakarma

Article History: Received: 11 January 2021; Accepted: 27 February 2021; Published online: 5 April 2021

\begin{abstract}
Renewable energy sources are becoming more and more popular, regarding the pollution and nonsustainability of common energy sources. The study mainly focused on the improvement of the PV collector performance by using ANSYS fluent. The design of the fin will change according to the previous study. In the current study, we will increase the thermal contact area of the fin by changing the design of the fin. The change in the design of the fin will increase the total heat transfer and efficiency of the system. It concluded that with betterdesigned fin arrangements, the required fan speed could be lowered for any number of fins or similar results could be obtained with fewer fins. On the other hand, since the power required by the PV-powered fan will also decrease with fewer fins and at lower air velocities, the total efficiency obtained from the PV system will also increase.
\end{abstract}

Keywords: solar PV, ANSYS, Computational Fluid Dynamics, temperature.

\section{INTRODUCTION}

Renewable energy sources are becoming more and more popular, regarding the pollution and non-sustainability of common energy sources. With increasing human population, a question arises, what is going to be the next reliable energy source after the disappearance of fossil fuels? One of most abundant resources is solar energy, which manifests itself directly, as solar irradiance, or indirectly as wind energy and biomass energy. When it comes to the efficiency of energy transformation, a couple of things need to be distinguished. There are two distinct types of energy that can be produced: electrical energy and thermal energy. Electrical energy, mostly because of its ability to be easily transferred to work, is more valuable than thermal energy. The most efficient way to obtain electrical energy is from direct solar irradiance via photovoltaic cells (PV cell). Although the overall efficiency of PV cells ranges from about $5 \%-20 \%$, it is still higher than the total indirect efficiency when it comes to wind and biomass efficiency. However, it has been shown that the overall efficiency of photovoltaic cells drops drastically with an increase in temperature. The rate of decrease ranges from $0.25 \%$ to $0.5 \%$ per degree Celsius, depending on the cell material used. Especially for concentrated PV cells, which use concentrated sunlight to produce larger amounts of power, and reduce the cost of generally expensive PV equipment, it has been observed that high temperatures greatly decrease the working life of the whole PV system. Cooling mechanisms have already been proposed [1-4] and the development of cooling techniques continues [5].

\section{LITERATURE REVIEW}

Pushpendu Dwivedi et al. [1] in this paper presented are the efficiency of solar systems, in particular photovoltaic panels, is generally low. The output of the P.V. module is adversely affected by their surface rise in temperature. This increase is associated with the absorbed sunlight that is converted into heat, resulting in reduced power output, energy efficiency, performance and life of the panel. The use of cooling techniques can offer a potential solution to avoid excessive heating of P.V. panels and to reduce cell temperature.

MuhammetKaan et al. [2] Demand for electricity generation from solar energy, which is a clean and renewable resource, is increasing day by day. It is desirable that the panel surface temperature is not excessively hot while generating electricity with PVT panels. High temperature causes thermal degradation and panel electric efficiency decrease.

A. N. Özakın et al. [3] The phenomenon of photovoltaic systems is based on the principals of semiconductor physics and they operate with a semiconductor element, such as silicon. 
Swapnil Dubey et al. [4] in this paper presented are the Solar cell performance decreases with increasing temperature, fundamentally owing to increased internal carrier recombination rates, caused by increased carrier concentrations. The operating temperature plays a key role in the photovoltaic conversion process. Both the electrical efficiency and the power output of a photovoltaic (PV) module depend linearly on the operating temperature.

Mansour NasiriKhalaji et al. [5] Demand for electricity generation from solar energy, which is a clean and renewable resource, is increasing day by day. It is desirable that the panel surface temperature is not excessively hot while generating electricity with PVT panels. High temperature causes thermal degradation and panel electric efficiency decrease.

Ziyad S Haidar et al. [6] this paper presents the results of an experimental study on the effect of cooling of solar photovoltaic (PV) panels by evaporative cooling. The evaporation latent heat was utilized to absorb the generated heat from the body of a PV module to reduce its temperature.

\section{OBJECTIVE}

- The effect of fins installed at the rear of a photovoltaic panel can be studied by using two types of fin to compute the efficiency and study it's effects on the performance of photovoltaic cell, in addition to that evaluate the efficiency for both types under study.

- Fin diameter, fin length, fin spacing and air velocity at the rear duct is taken into account in this investigation about the photovoltaic panel.

- The study mainly focused on the improvement of the PV collector performance by using ANSYS fluent.

- The design of the fin will change according to the previous study. In the current study we will increase the thermal contact area of the fin by changing the design of the fin. Due to the change in the design of the fin, it will increase the total heat transfer and efficiency of the system.

\section{METHODOLOGY}

In this study the mathematical model of the PVT collector was designed by catiaV5.and CFD analysis preformed on ANSYS fluent. ANSYS software was used for calculating the performance of the PVT Collector.

A. CFD Analysis on PV Collector.

Preparation of model:CAD model is prepared in catia

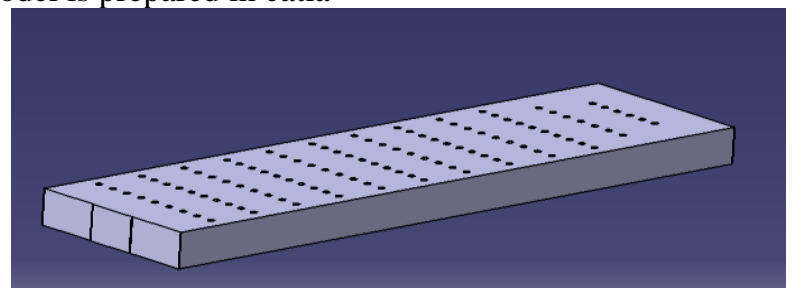

Fig. 1 Catia model design of PV collector

B. Steps Of Working

Step 1: Collecting information and data related to PV Collector

Step 2: A fully parametric model of the PV collector for 3 cases.

Step 3: Model obtained in Step 2 is analyzed using ANSYS 18.2.

Step4: Finally, we compare the results obtained from ANSYS.

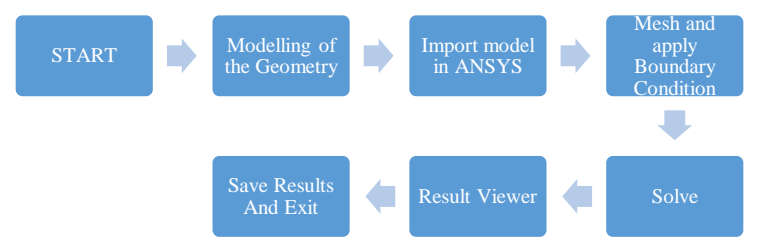

C. CFD Governing Equations

Fig. 2 Setup of working

Navier-Stokes Equations: -The Navier-Stokes equations are the fundamental partial differentials equations that describe the flow of incompressible fluids. Using the rate of stress and rate of strain tensors, it can be shown that the components of a viscous force $\mathrm{F}$ in a nonrotating frame are given by 


$$
\begin{aligned}
& \frac{F_{i}}{V}=\frac{\partial}{\partial x j}\left[\mathrm{n}\left(\frac{\partial u_{i}}{\partial x_{j}}+\frac{\partial u_{j}}{\partial x_{i}}\right)+\lambda \delta_{\mathrm{ij}} \Delta . \mathrm{u}\right] \\
& =\frac{\partial}{\partial x j}\left[\mathrm{n}\left(\frac{\partial u_{i}}{\partial x_{j}}+\frac{\partial u_{j}}{\partial x_{i}}-{ }_{3}^{2} \delta \mathrm{ij} \Delta . \mathrm{u}\right)+\mu \mathrm{B} \delta \mathrm{ij} \Delta . \mathrm{u}\right]
\end{aligned}
$$

D. Steps of ANSYS Analysis

The different analysis steps involved in ANSYS are mentioned below.

1. Preprocessor

The model setup is basically done in preprocessor. The different steps in pre-processing are

- $\quad$ Build the model

- Define materials

- Generation of element mesh

2. BUILDING THE MODEL

- Creating a solid model within Catia

- First creating air domain according to base paper. The panel size is $55 \mathrm{~cm}$ wide and $120 \mathrm{~cm}$ in length.

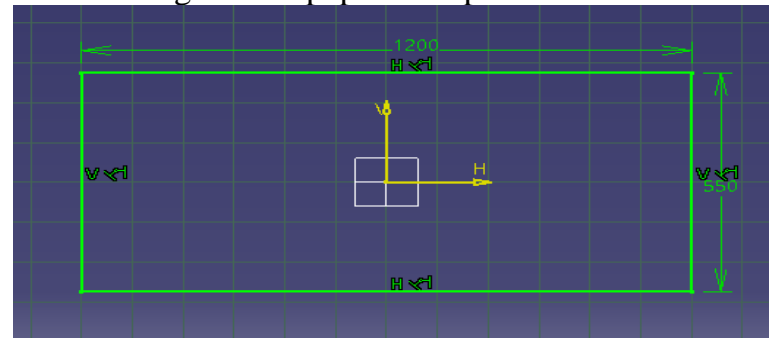

Fig. 3 CAD model prepared in Catia (base paper model)

- Fig. 3 show the fin arrangement and fin design according base paper model.so first create cad model of the fin by using cad software Catia.

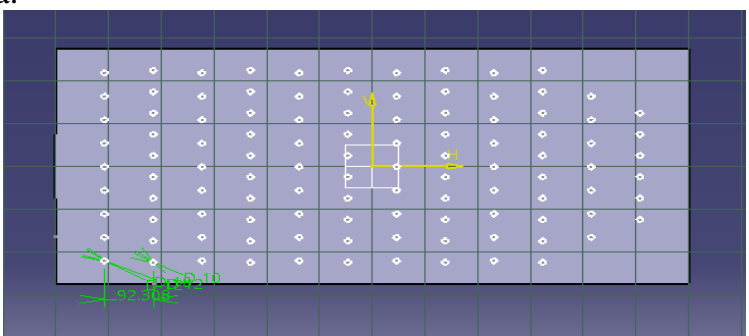

Fig. 4 CAD model prepared in Catia (base paper model)

3. Import Model in ANSYS

After completing the modeling in Catia. Then import model in ANSYS in ST. Format.

Fig. 4 shows the Ansys model.

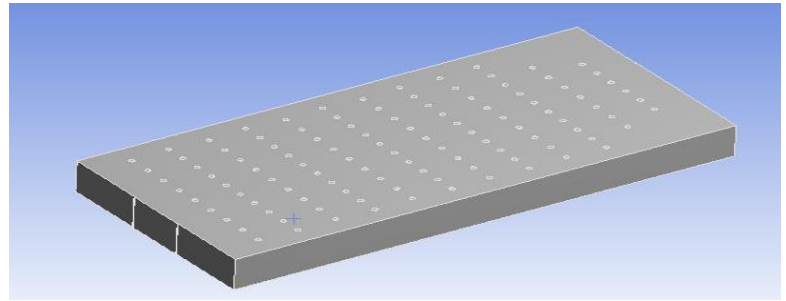

E. Material and Methodology

Fig. 5 Import model in ANSYS

Below table show the design parameter of the PVT collector. The cad model developed with help of the given design Parameters.

Table 1: -Material and Methodology [1]

\begin{tabular}{|l|l|}
\hline Panel size & 1200 X550 \\
\hline Number of fins & $\begin{array}{l}\text { Odd rows and even } \\
\text { rows have 9 and 10 } \\
\text { fins }\end{array}$ \\
\hline
\end{tabular}


F. The k-epsilon Model

\begin{tabular}{|l|l|}
\hline Vertical spacing & $5 \mathrm{~cm}$ \\
\hline Horizontal spacing & $5.5 \mathrm{~cm}$. \\
\hline Fin diameter & $12 \mathrm{~mm}$ \\
\hline length & $50 \mathrm{~mm}$ \\
\hline Specific weight $(\mathrm{kg} / \mathrm{dm} 3)$ & 8.9 \\
\hline $\begin{array}{l}\text { Thermal conductivity } \\
(\mathrm{W} / \mathrm{m} \cdot \mathrm{K})\end{array}$ & 336 \\
\hline Melting point $\left({ }^{\circ} \mathrm{C}\right)$ & $1065-1085$ \\
\hline $\begin{array}{l}\text { Specific heat capacity } \\
(\mathrm{kcal} / \mathrm{kg} \cdot \mathrm{K})\end{array}$ & 0.092 \\
\hline
\end{tabular}

- One of the most prominent turbulence models, the $k$-epsilon model, has been implemented in most general purpose CFD codes and is considered the industry standard model. It has proven to be stable and numerically robust and has a well-established regime of predictive capability. For general purpose simulations, the $k$-epsilon model offers a good compromise in terms of accuracy and robustness.

- Within CFD, the $k$-epsilon turbulence model uses the scalable wall-function approach to improve robustness and accuracy when the near-wall mesh is very fine. The scalable wall functions enable solutions on arbitrarily fine near-wall grids, which is a significant improvement over standard wall functions.

- While standard two-equation models, such as the $k$-epsilon model, provide good predictions for many flows of engineering interest, there are applications for which these models may not be suitable. Among these are:

- Flows with boundary layer separation.

- Flows with sudden changes in the mean strain rate.

- Flows in rotating fluids.

- Flows over curved surfaces.

- A Reynolds stress model may be more appropriate for flows with sudden changes in strain rate or rotating flows, while the SST model may be more appropriate for separated flows.

The exact k- $\varepsilon$ equations contain many unknown and unmeasurable terms. For a much more practical approach, the standard k- $\varepsilon$ turbulence model (Launder and Spalding, 1974[3]) is used which is based on our best understanding of the relevant processes, thus minimizing unknowns and presenting a set of equations which can be applied to a large number of turbulent applications.

For turbulent kinetic energy-k.

$$
\frac{\partial(p k)}{\partial t}+\frac{\partial(p k u i)}{\partial x_{i}}=\frac{\partial}{\partial x_{j}}\left[\frac{\mu t}{\sigma k} \frac{\partial k}{\partial x i}\right]+2 \mu \mathrm{tE}_{\mathrm{ij}} \mathrm{E}_{\mathrm{ij}}-\rho \varepsilon
$$

For dissipation $\varepsilon$

$$
\frac{\delta(p \varepsilon)}{\delta t}+\frac{\partial(\rho \varepsilon u i)}{\partial x_{i}}=\frac{\partial}{\partial x_{j}}\left[\frac{\mu_{t}}{\sigma \varepsilon} \frac{\partial \epsilon}{\partial x j}\right]+C 1 \varepsilon \frac{\epsilon}{k} 2 \mu t \text { EijEij }-\mathrm{C} 2 \varepsilon \rho \frac{\epsilon^{2}}{k}
$$

Where

$\mu \mathrm{i}$ represented velocity component in corresponding direction

Eij represents component of rate of deeformation

$\mu \mathrm{t}$ represented eddy viscosity

$$
\mu \mathrm{t}=\rho \mathrm{C} \mu \frac{K^{2}}{\epsilon}
$$

Case-1:-simple fin

In case first base model was created by using Catia software after modeling the cad model import into ansys.in first case the simple fin model was used for the validations study. Figure 6 shows the simple fin model with whole model. 


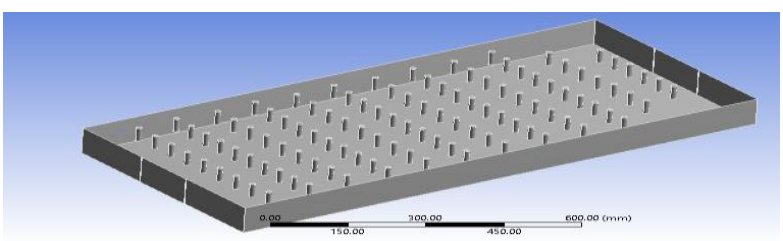

Fig. 6: Case-1 model

Case-2 Perforated fin model $8 \mathrm{~mm}$ diameter.

After case-1 in case- 2 holes was created shown in fig 7.the $8 \mathrm{~mm}$ holes was created on the fin. The holes increase the area of contact. The perforated fin increase the heat transfer rate.

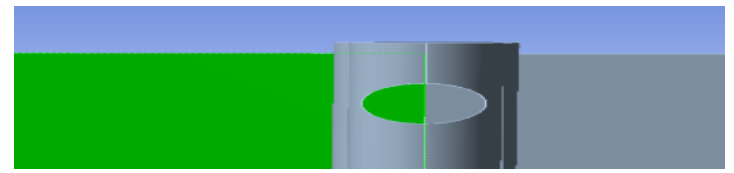

Fig. $78 \mathrm{~mm}$ hole

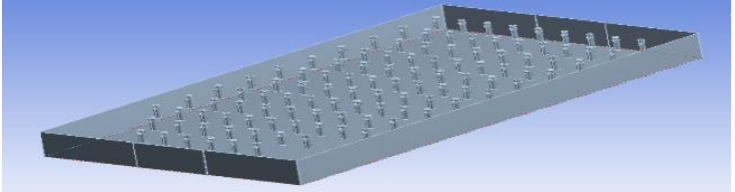

Fig. 8 Perforated fin model (Hole diameter 8mm)

Case-3 Perforated fin model $6 \mathrm{~mm}$ diameter.

case-3 holes was created shown in fig4.9.the $6 \mathrm{~mm}$ holes was created on the fin. The holes increase the area of contact.

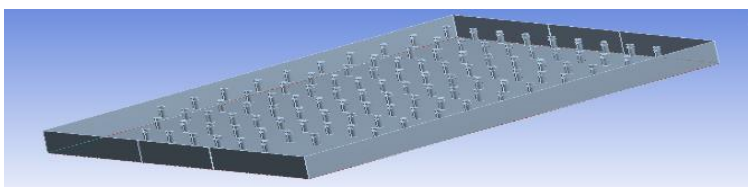

Fig. 9 Perforated fin model (Hole diameter $6 \mathrm{~mm}$ )

Case-4 Perforated fin model $4 \mathrm{~mm}$ diameter.

case-4 holes was created shown in fig 10.the $4 \mathrm{~mm}$ holes was created on the fin. The holes increase the area of contact.

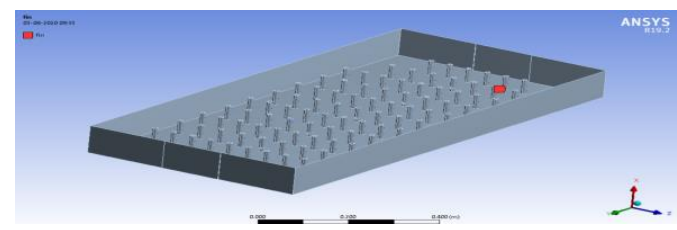

Fig. 10 Perforated fin model $4 \mathrm{~mm}$ diameter

Case-5 Perforated fin model $2 \mathrm{~mm}$ diameter.

Case-5 holes was created shown in fig 11.the $2 \mathrm{~mm}$ holes was created on the fin. The holes increase the area of contact.

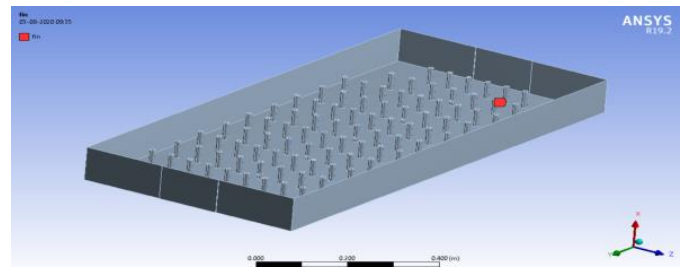

4. MESHING

Fig. 11 Perforated fin model $2 \mathrm{~mm}$ diameter

Meshing is an integral part of the engineering simulation process where complex geometries are divided into simple elements that can be used as discrete local approximations of the larger domain. The mesh influences the accuracy, convergence and speed of the simulation. Furthermore, since meshing typically consumes a significant portion of the time it takes to get simulation results, the better and more automated the meshing tools, the faster and more accurate the solution. 
Ansys provides general purpose, high-performance, automated, intelligent meshing software which produces the most appropriate mesh for accurate, efficient multiphysics solutions - from easy, automatic meshing to highly crafted mesh. Methods available cover the meshing spectrum of high-order to linear elements and fast tetrahedral and polyhedral to high-quality hexahedral and Mosaic. Smart defaults are built into the software to make meshing a painless and intuitive task delivering the required resolution to capture solution gradients properly for dependable results.

Case-1: In case-1 total number of elements 4944832 and total number of nodes 933507.the elements and nodes are shown in fig4.12.

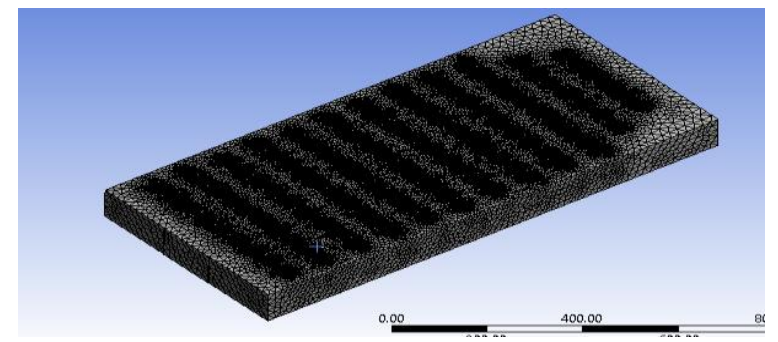

Fig. 12: Meshing: Total No. of Nodes: 933507\& Total No. elements: 4944832

Case-2: In case-2 total number of elements737442and total number of nodes 140034.the elements and nodes are shown in fig 13.

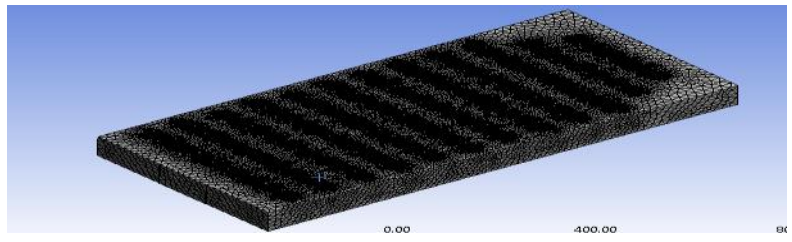

Fig. 13 Meshing: Total No. of Nodes: $140034 \&$ Total No. elements: 737442

Case-3: In case-3 total number of elements 737442 and total number of nodes 140034.the elements and nodes are shown in fig 14.

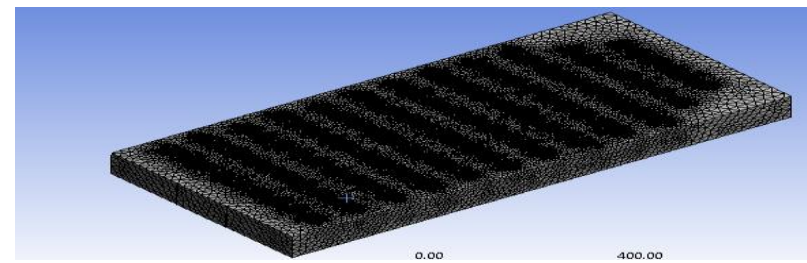

Fig. 14 Meshing: Total No. of Nodes: 140034\& Total No. elements: 737442

Case-4: In case-3 total number of elements 1123269 and total number of nodes 5978466.the elements and nodes are shown in fig 15.

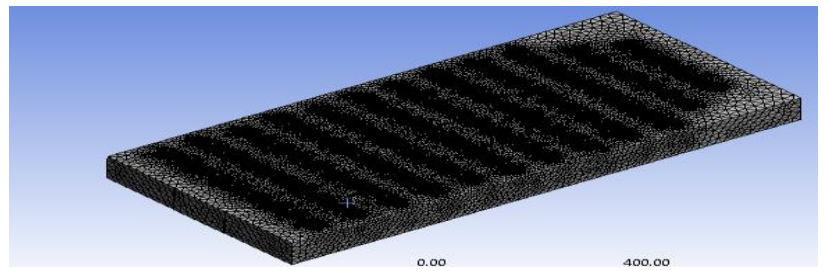

Fig. 16: Meshing: Total No. of Nodes: $1123269 \&$ Total No. elements: 5978466

Case-5: In case-3 total number of elements 1221581 and total number of nodes 1221581.the elements and nodes are shown in fig 17.

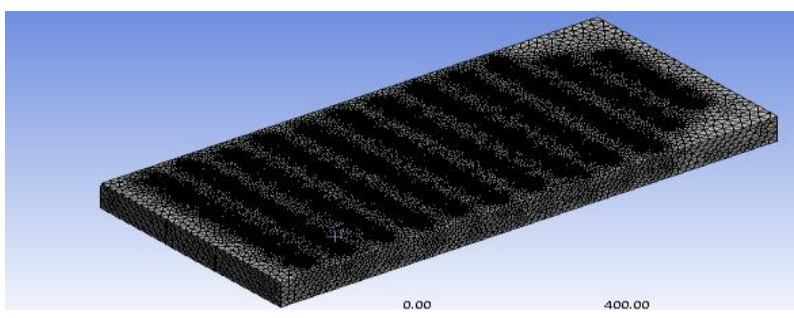

Fig. 17: Meshing: Total No. of Nodes: $1221581 \&$ Total No. elements: 1221581

5. Defining Material Properties 


\section{Copper properties}

Air properties

\begin{tabular}{|c|c|}
\hline Properties & Value \\
\hline Density $\left(\mathrm{kg} / \mathrm{m}^{\wedge} 3\right)$ & 8978 \\
\hline Specific heat $(\mathrm{j} / \mathrm{kg}-\mathrm{k})$ & 381 \\
\hline Thermal conductivity(w/m-k) & 387.6 \\
\hline
\end{tabular}

Table 2. - Copper Properties [1]

\begin{tabular}{|c|c|}
\hline Properties & Values \\
\hline Density $\left(\mathrm{kg} / \mathrm{m}^{\wedge} 3\right)$ & 1.225 \\
\hline Specific heat $(\mathrm{j} / \mathrm{kg}-\mathrm{k})$ & 1006.43 \\
\hline $\begin{array}{c}\text { Thermal conductivity }(\mathrm{w} / \mathrm{m}- \\
\mathrm{k})\end{array}$ & 0.0242 \\
\hline
\end{tabular}

Table 3:- Air Properties [1]

4.5 Boundary Condition

A fan with $10 \mathrm{~W}$ of power has been employed to feed more air through the control volume in order to create forced convection, and ambient air, used as the working fluid, was sucked through the air duct of the test setup, as shown in Fig. 18.(a)

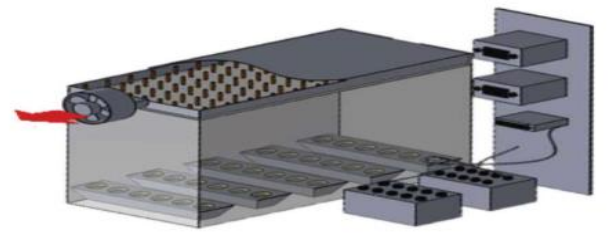

Fig. 18Base paper Experimental setup(a)[1]

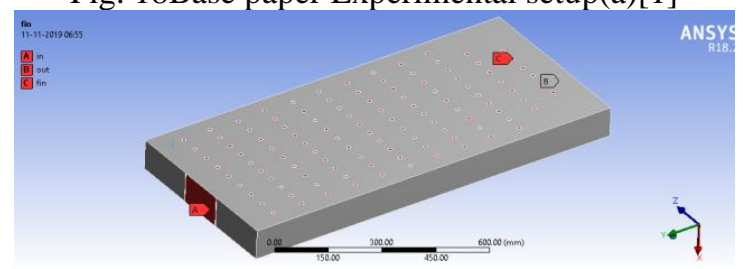

Fig. 19 Define boundary conditions(b)

\begin{tabular}{|c|c|}
\hline Boundary conditions & Values \\
\hline Inlet velocity & $4.5 \mathrm{~m} / \mathrm{s}$ \\
\hline Outlet & Pressure outlet \\
\hline The amount of radiation was kept constant at $\mathrm{Q}_{\text {solar }}$ & $1100 \mathrm{~W} / \mathrm{m}^{2}$ \\
\hline
\end{tabular}

Table 4:-boundary conditions for CFD analysis [1]

Case-1 Result

Velocity contours: - This simulation was run using the k- $\varepsilon$ turbulence model. The purpose of running this simulation was to determine the role that a turbulence model played in the results. The maximum velocity $5.04 \mathrm{~m} / \mathrm{s}$ in first case. The blue color shows minimum velocity area. And the yellow color show maximum velocity area. 


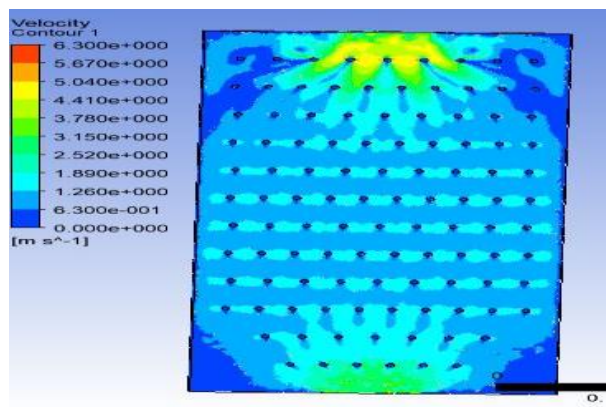

Fig. 20: Velocity contours for case-1

Temperature contours: -The temperature contours shows the temperature distribution inside the PV collector. Maximum temperature inside the collector was 393K and minimum temperature 318.6k.the light blue color show the minimum temperature region and red color show maximum temperature region.

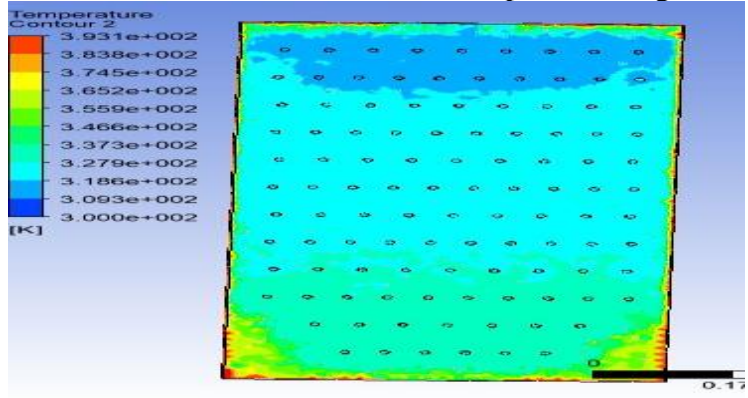

Fig. 21: Temperature contours for case-1

Pressure contours: the pressure contour use to identify the pressure distribution inside the PV collector. The pressure inside the PVT collector depended on heat transfer rate and air flow. The red color in fig show the maximum pressure zone and blue color minimum pressure zone.

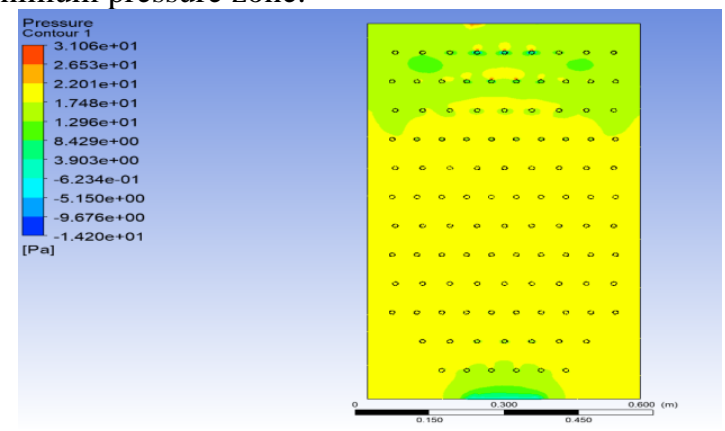

Fig. 22 pressure contours for case-1

Velocity stream line:- Streamline, In fluid mechanics, the path of imaginary particles suspended in the fluid and carried along with it. In steady flow, the fluid is in motion but the streamlines are fixed. Where streamlines crowd together, the fluid speed is relatively high; where they open out, the fluid is relatively still. See also laminar flow, turbulent flow. velocity streamline shows the flow of air inside the collector

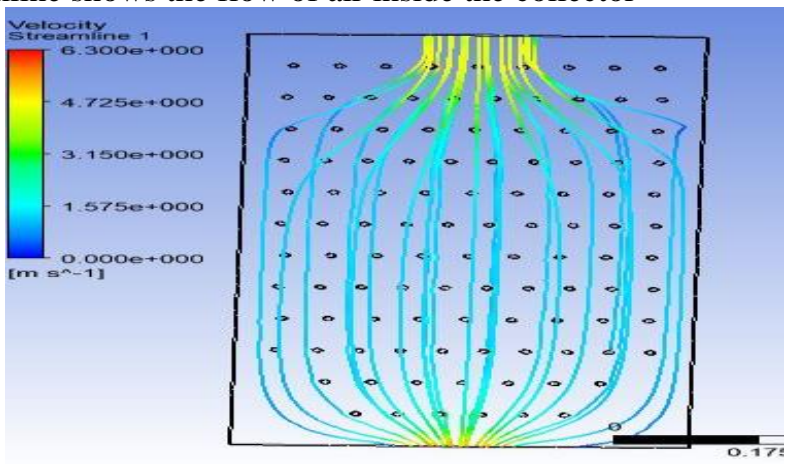


Fig. 23: Velocity stream line for case-1

Direction of the flow:-The below fig show the direction of the flow. The vector stream line show the flow and the direction of flow.

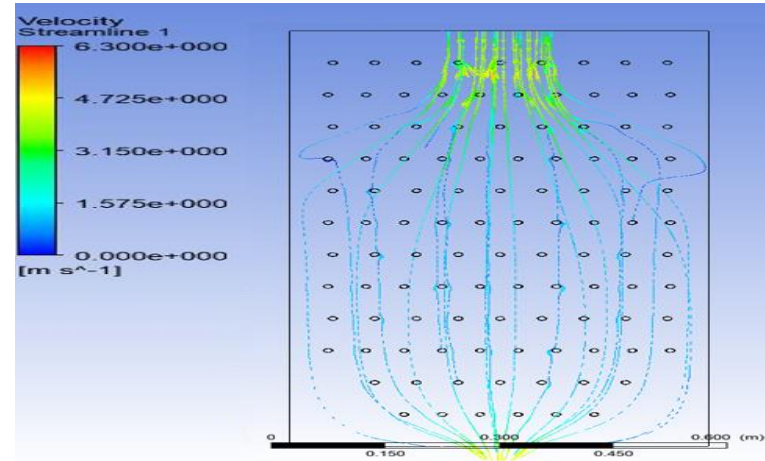

Fig. 24 Vector stream line for case-1

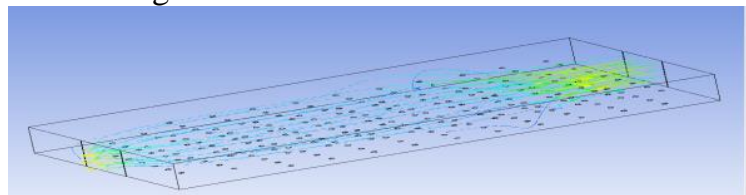

Fig. 25 direction flow vector stream line for case-1

Case-2 Result:-

Temperature contours:- The temperature contours shows the temperature distribution inside the PV collector. maximum temperature inside the collector was $393 \mathrm{~K}$ and minimum temperature $360.1 \mathrm{k}$. the light blue color show the minimum temperature region and red color show maximum temperature region.

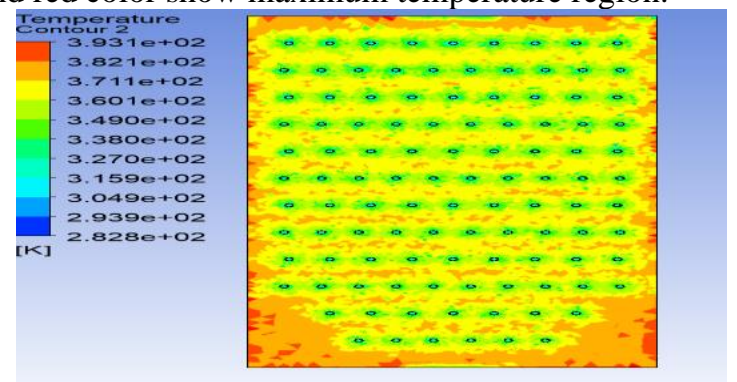

Fig. 26: Temperature contours for case-2

Velocity contours:-maximum velocity inside the collector was $5.85 \mathrm{~m} / \mathrm{s}$. The light blue color show the minimum velocity region and red color show maximum velocity region.

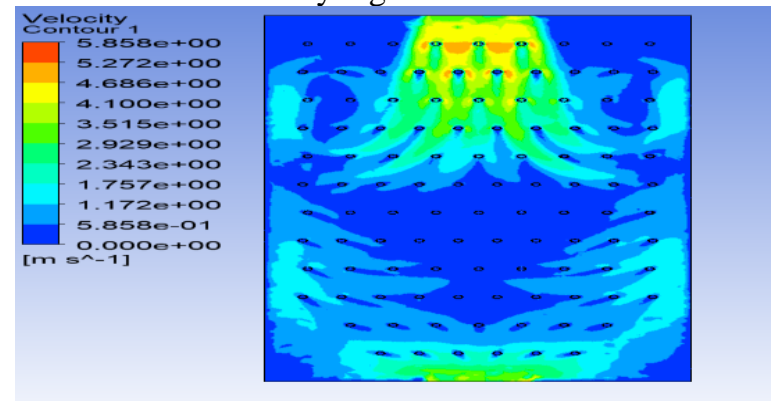

Fig. 27: Velocity contours for case-2

Streamline: - Streamline, in fluid mechanics, the path of imaginary particles suspended in the fluid and carried along with it. In steady flow, the fluid is in motion but the streamlines are fixed. Where streamlines crowd together, the fluid speed is relatively high; where they open out, the fluid is relatively still. See also laminar flow, turbulent flow.Velocity streamline shows the flow of air inside the collector. The flow of air inside the pvt collector shown by stream line. The maximum velocity 5.85 inside the pvt collector 


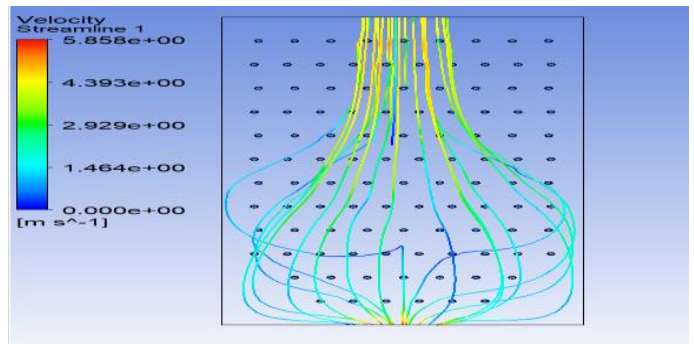

Fig. 28: Velocity stream line for case-2

Direction of the flow:-The below fig show the direction of the flow. The vector stream line show the flow and the direction of flow.

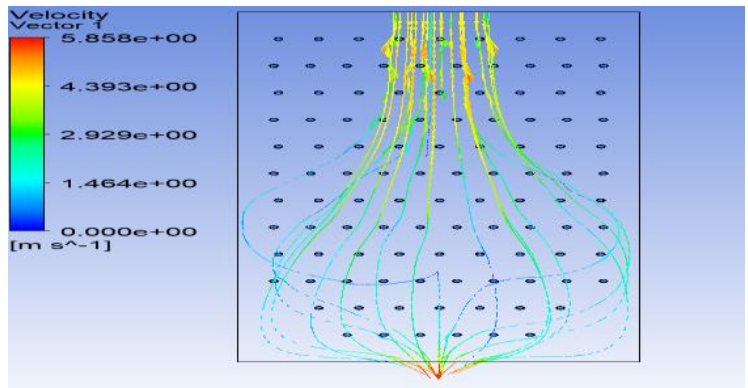

Fig. 29 Vector stream line for case-2

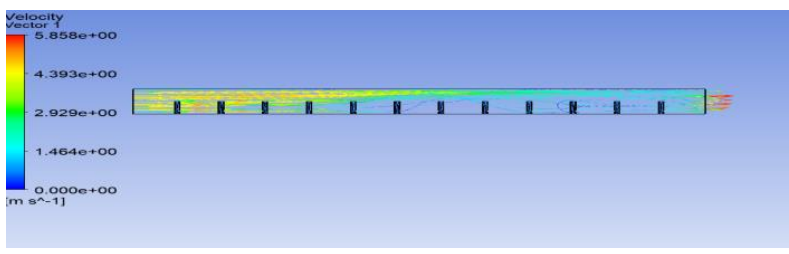

Fig. 30 Vector stream line for case-2

Pressure contours:-the pressure contour use to identify the pressure distribution inside the PV collector. The The pressure inside the pvt collector depended on heat transfer rate and air flow. The red color in fig show the maximum pressure zone and blue color minimum pressure zone.

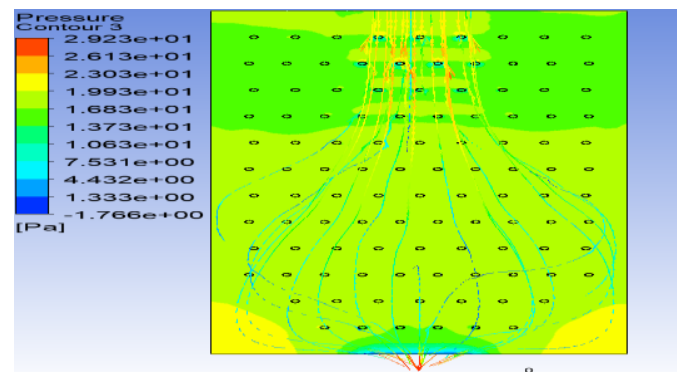

Fig. 31 pressure contours for case-2

Case-3 Result:-

Temperature contours:- The temperature contours shows the temperature distribution inside the PV collector. maximum temperature inside the collector was $393 \mathrm{~K}$ and minimum temperature $337.9 \mathrm{k}$.the light blue color show the minimum temperature region and red color show maximum temperature region. 


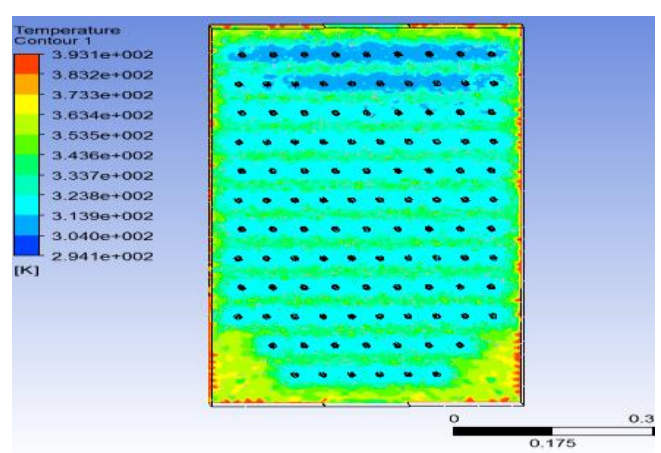

Fig. 32: Temperature contours for case-3

Velocity contours:-maximum velocity inside the collector was $8.68 \mathrm{~m} / \mathrm{s}$. The light blue color show the minimum velocity region and red color show maximum velocity region.

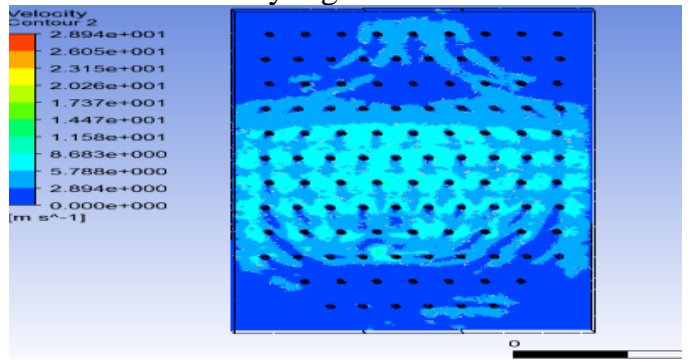

Fig. 33: Velocity contours for case-3

Streamline: - Streamline, In fluid mechanics, the path of imaginary particles suspended in the fluid and carried along with it. In steady flow, the fluid is in motion but the streamlines are fixed. Where streamlines crowd together, the fluid speed is relatively high; where they open out, the fluid is relatively still. See also laminar flow, turbulent flow. velocity streamline shows the flow of air inside the collector line. The flow pattern of the air dependent of the air velocity and air domain. The maximum velocity $2.89 \mathrm{~m} / \mathrm{s}$ inside the pvt collector
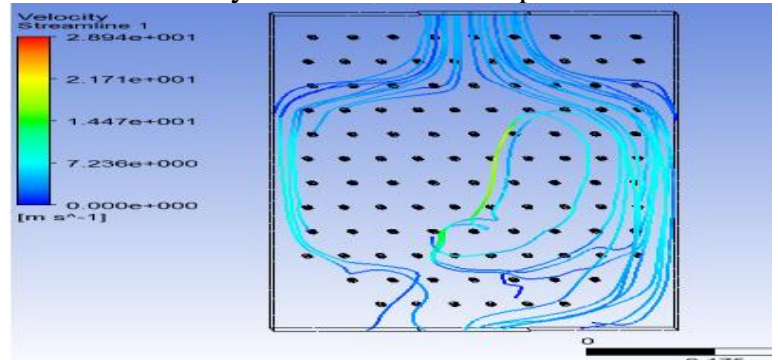

Fig. 34: Velocity stream line for case-3

Direction of the flow:-The below fig show the direction of the flow. The vector stream line show the flow and the direction of flow.

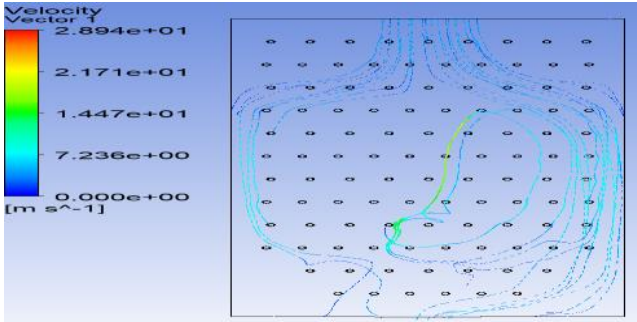

Fig. 35: Velocity stream line for case-3

Pressure contours:-The pressure contour use to identify the pressure distribution inside the PV collector. The pressure inside the pvt collector depended on heat transfer rate and air flow. The red color in fig show the maximum pressure zone and blue color minimum pressure zone. 
Case-4 Result:-

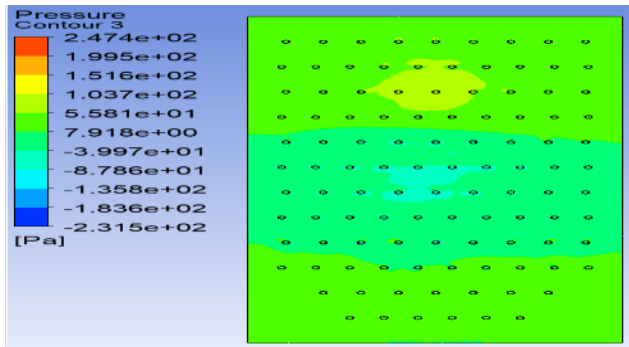

Fig. 36: Pressure contours for case-3

Temperature contours:- The temperature contours shows the temperature distribution inside the PV collector. maximum temperature inside the collector was $393 \mathrm{~K}$ and minimum temperature 330k.the light blue color show the minimum temperature region and red color show maximum temperature region.

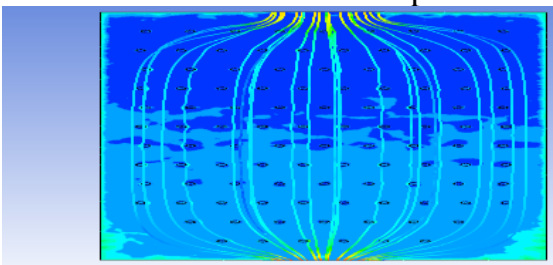

Fig. 37: Temperature contours for case-4

Velocity contours: -maximum velocity inside the collector was $5.61 \mathrm{~m} / \mathrm{s}$. The light blue color show the minimum velocity region and red color show maximum velocity region.

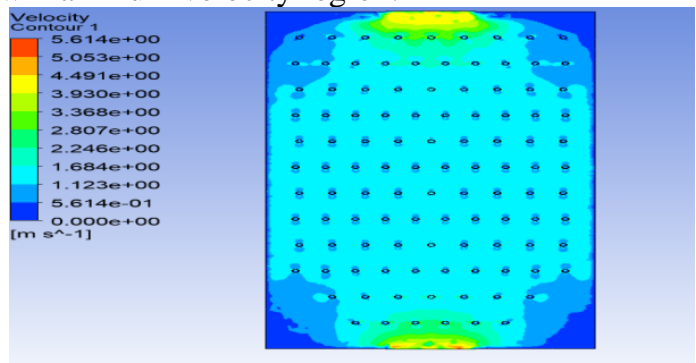

Fig. 38: Velocity contours for case-4

Streamline: - Streamline, In fluid mechanics, the path of imaginary particles suspended in the fluid and carried along with it. In steady flow, the fluid is in motion but the streamlines are fixed. Where streamlines crowd together, the fluid speed is relatively high; where they open out, the fluid is relatively still. See also laminar flow, turbulent flow. velocity streamline shows the flow of air inside the collector
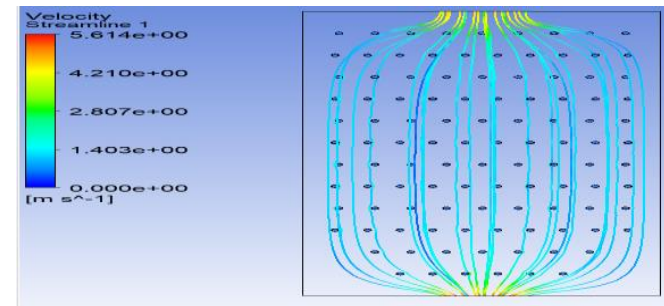

Fig. 39: Velocity stream line for case-4

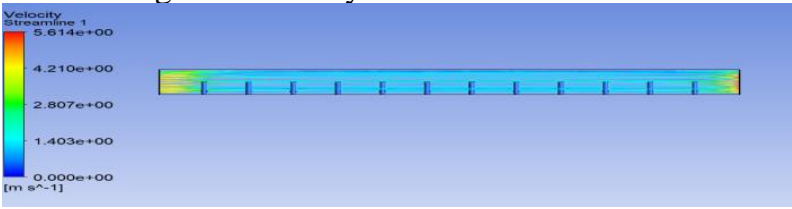

Fig. 40: Velocity stream line for case-4

Direction of the flow:-The below fig show the direction of the flow. The vector stream line show the flow and the direction of flow. 


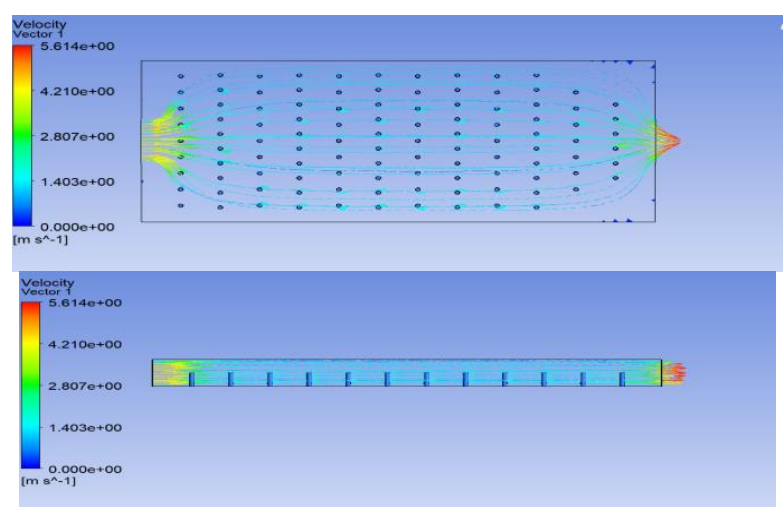

Fig. 41: Vector stream line for case-4

Pressure contours:-the pressure contour use to identify the pressure distribution inside the PV collector. The pressure inside the pvt collector depended on heat transfer rate and air flow. The red color in fig show the maximum pressure zone and blue color minimum pressure zone.

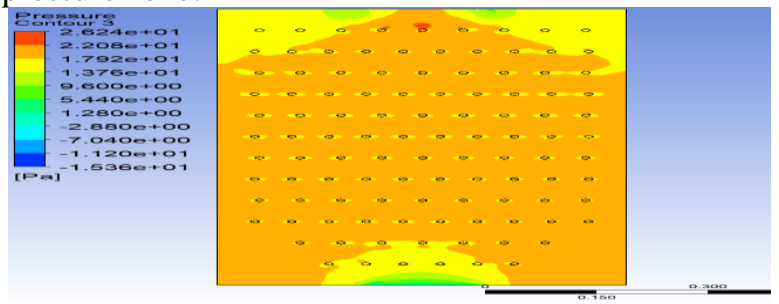

Case-5 Result:-

Fig. 42: Pressure contours for case-4

Temperature contours:- The temperature contours shows the temperature distribution inside the PV collector. maximum temperature inside the collector was $393 \mathrm{~K}$ and minimum temperature $320 \mathrm{k}$.the light blue color show the minimum temperature region and red color show maximum temperature region.

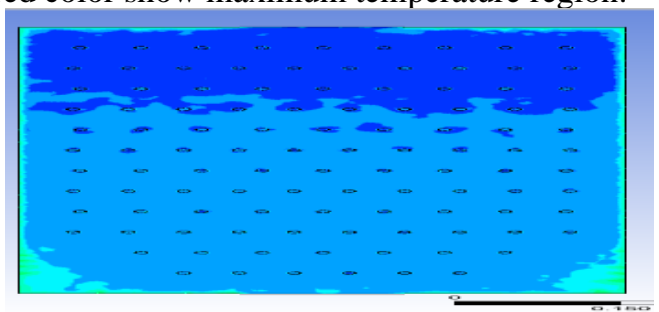

Fig. 43: Temperature contours for case-5

Velocity contours:-maximum velocity inside the collector was $5.567 \mathrm{~m} / \mathrm{s}$. The light blue color show the minimum velocity region and red color show maximum velocity region.

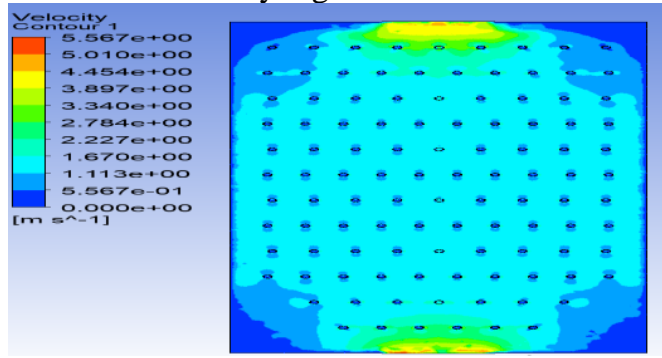

Fig. 44: Velocity contours for case-5

Streamline: - Streamline, In fluid mechanics, the path of imaginary particles suspended in the fluid and carried along with it. In steady flow, the fluid is in motion but the streamlines are fixed. Where streamlines crowd together, the fluid speed is relatively high; where they open out, the fluid is relatively still. See also laminar flow, turbulent flow velocity 


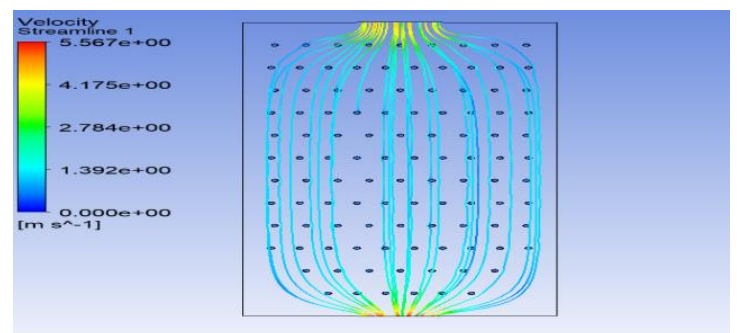

Fig. 45: Velocity stream line for case-5

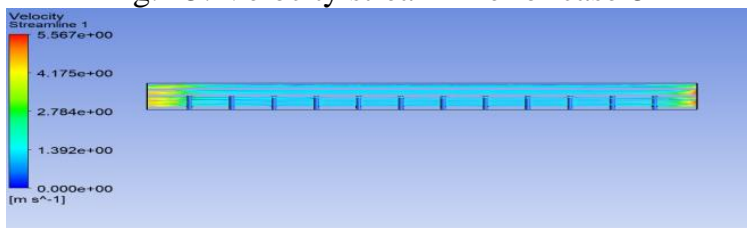

Fig. 46: Stream line direction of the flow for case-5

Direction of the flow:-The below fig show the direction of the flow. The vector stream line show the flow and the direction of flow.

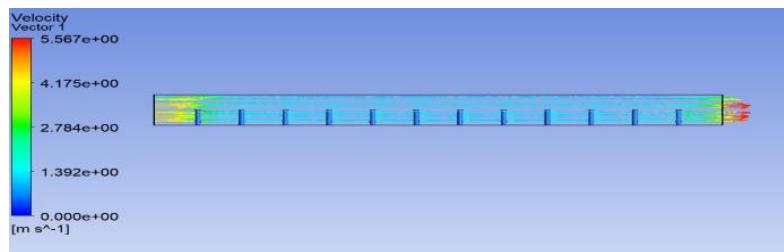

Fig. 47: Direction of the flow for case-5

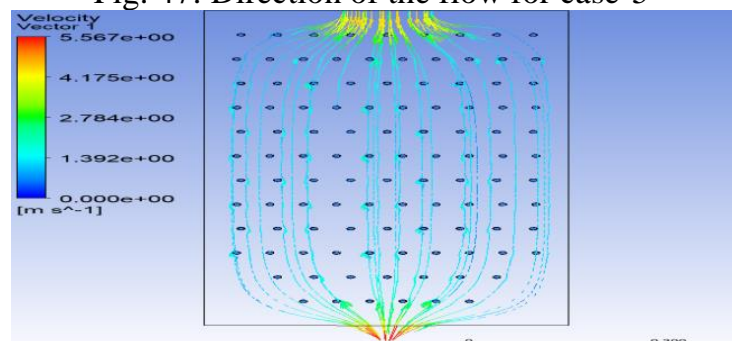

Fig. 48: Direction of the flow for case-5

Pressure contours:-the pressure contour use to identify the pressure distribution inside the PV collector. The pressure inside the pvt collector depended on heat transfer rate and air flow. The red color in fig show the maximum pressure zone and blue color minimum pressure zone.

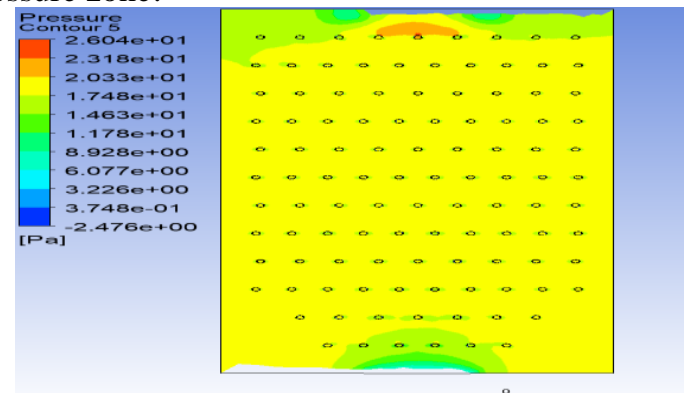

Fig. 49: Pressure contours for case-5

Validations

In the validations first, we create the base paper model and validated to paper result. Figure 4.48 show that paper result and figure 50 show the validation result.in figure 50(a) temperature contours result and figure 50(b) velocity contours. And in figure 51 (a) is temperature contours and figure 51(b) velocity contours. After comparing base paper and validations result. The maximum temperature show in figure 51(a) and the maximum temperature in figure 51(b) were the same. 


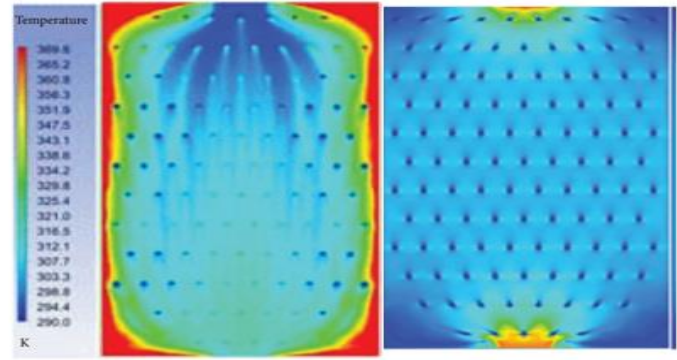

Fig. 50 base Paper (a) maximum temperature (b) velocity

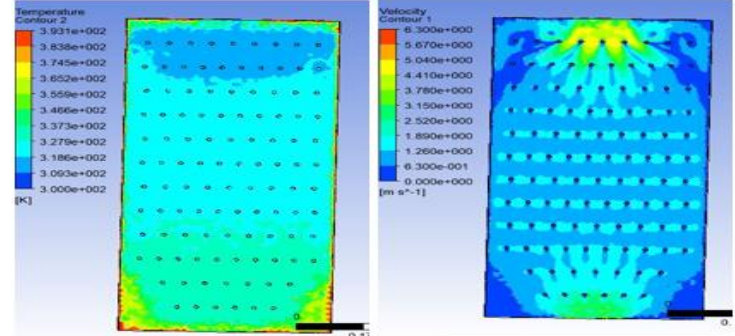

Fig. 51 Current Study (a) Paper maximum temperature (b) velocity

The upper figure show the temperature contours of current study and previous study. Fig(a) show the maximum temperature 393k and figure (b) also show the same temperature. And velocity contours in current study match with previous study.in both study maximum velocity obtain on the inlet of the collector.

\section{RESULTS}

Result shows, a cooling of up to 60-65 degrees at the surface temperature of 120 degrees has been achieved, so the decrease in the electrical current is prevented to a great extent and the efficiency could be maintained. Consequent turbulent air flows occurring within the control volume, especially in the vicinity of the fins, contributes to heat removal from the panel; therefore, with the CASE-2 arrangement, the highest thermal efficiency was achieved $81 \%$ as expected.

\begin{tabular}{|c|c|c|c|c|c|}
\hline & $\begin{array}{l}\text { Outl } \\
\text { et } \\
\text { velo } \\
\text { city( } \\
\mathrm{m} / \mathrm{s})\end{array}$ & $\begin{array}{l}\text { Mas } \\
\mathrm{s} \\
\text { flow } \\
\text { rate( } \\
\mathrm{kg} / \mathrm{s})\end{array}$ & $\begin{array}{l}\text { Outlet } \\
\text { Temper } \\
\text { ature (k) }\end{array}$ & $\begin{array}{l}\text { inlet } \\
\text { Temper } \\
\text { ature(k) }\end{array}$ & $\begin{array}{l}\text { Ther } \\
\text { mal } \\
\text { effici } \\
\text { ency }\end{array}$ \\
\hline $\begin{array}{l}\text { CASE } \\
-1 \\
\end{array}$ & 1.05 & $\begin{array}{l}0.01 \\
94 \\
\end{array}$ & 322 & 300 & 0.47 \\
\hline $\begin{array}{l}\text { CASE } \\
-2 \\
\end{array}$ & 1.74 & $\begin{array}{l}0.03 \\
2 \\
\end{array}$ & 323 & 300 & $\begin{array}{l}0.81 \\
7 \\
\end{array}$ \\
\hline $\begin{array}{l}\text { CASE } \\
-3 \\
\end{array}$ & $\begin{array}{l}1.57 \\
8 \\
\end{array}$ & $\begin{array}{l}0.02 \\
9 \\
\end{array}$ & 322 & 300 & $\begin{array}{l}0.70 \\
8 \\
\end{array}$ \\
\hline $\begin{array}{l}\text { CASE } \\
-4\end{array}$ & $\begin{array}{l}1.34 \\
1\end{array}$ & $\begin{array}{l}0.02 \\
6 \\
\end{array}$ & 320 & 300 & 0.58 \\
\hline $\begin{array}{l}\text { CASE } \\
-5\end{array}$ & 1.2 & $\begin{array}{l}0.02 \\
205\end{array}$ & 323 & 300 & 0.56 \\
\hline
\end{tabular}

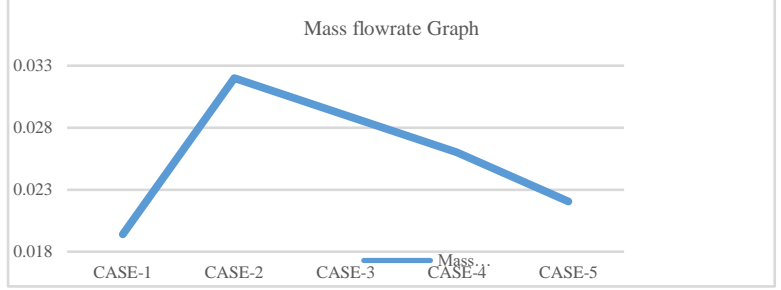

Graph 1: _Mass flow rate Graph

Graph 1 show the mass flow rate. The case-2 shows the mass flow rate. The graph 1 show the mass flow rate in different cases. 


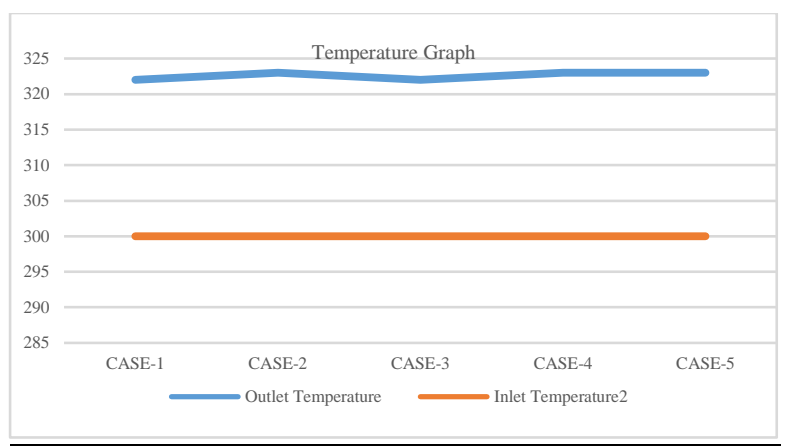

Graph 2: Comparative result of Inlet outlet Temperature graph

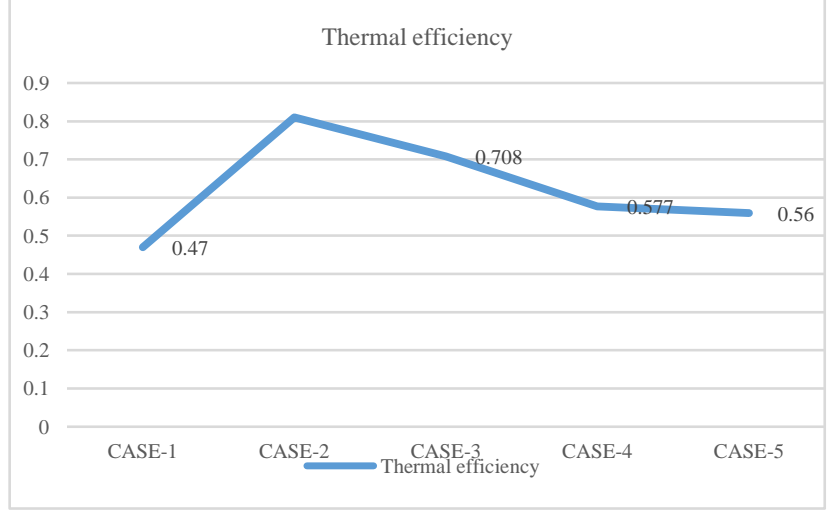

Graph 3: Thermal efficiency graph

Temperature inside the PVT collector case-1 shows minimum and case-2 show maximum

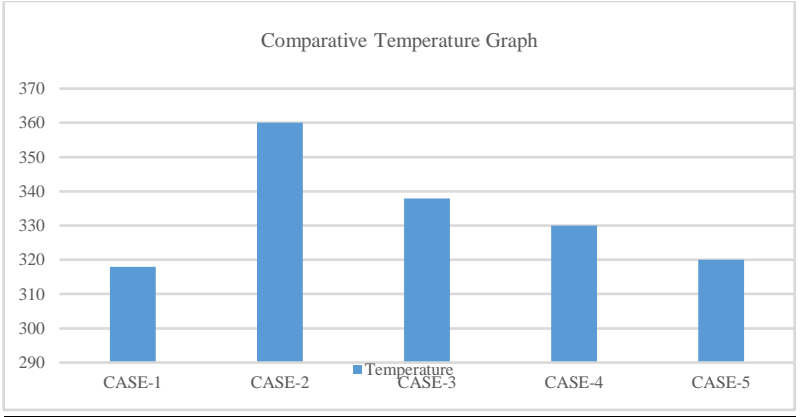

Graph 4: -Temperature graph

\begin{tabular}{|c|c|c|c|c|c|}
\hline & CASE- & $\begin{array}{l}\text { CASE- } \\
2\end{array}$ & $\begin{array}{l}\text { CASE- } \\
3 \\
\end{array}$ & $\begin{array}{l}\text { CASE- } \\
4 \\
\end{array}$ & $\begin{array}{l}\text { CASE- } \\
5\end{array}$ \\
\hline $\begin{array}{l}\text { inlet } \\
\text { velocity }\end{array}$ & 4.5 & 4.5 & 4.5 & 4.5 & 4.5 \\
\hline $\begin{array}{l}\text { Outlet } \\
\text { velocity }\end{array}$ & 1.05 & 1.74 & 1.578 & 1.341 & 1.2 \\
\hline
\end{tabular}



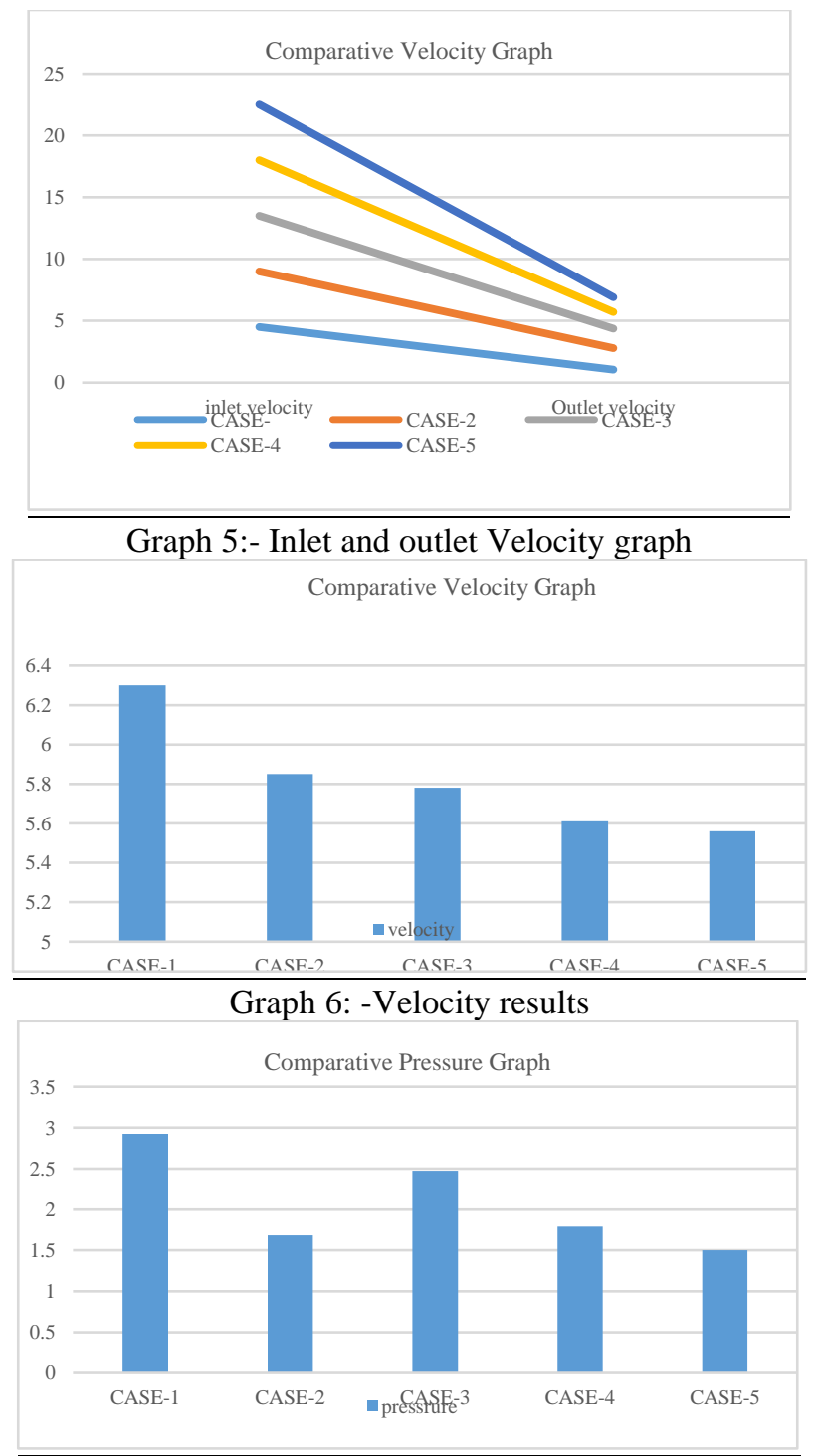

Graph 7: -Comparative Pressure graph

\section{CONCLUSION}

- The efficiency of the PV panel without active cooling decreases in relation to increasing surface temperature when the panel is not cooled, the forced convection heat transfer zone is formed in the control volume in the back of the PV panel.

- As a result, a cooling of up to 60-65 degrees at the surface temperature of 120 degrees has been achieved, so the decrease in the electrical current is prevented to a great extent and the efficiency could be maintained.

- Consequent turbulent air flows occurring within the control volume, especially in the vicinity of the fins, contributes to heat removal from the panel; therefore, with the CASE-2 arrangement, the highest thermal efficiency was achieved $81 \%$ as expected.

- The heat transfer rate in case-2 maximum and case- 1 is minimum.

- The perforated fin increase the overall efficiency of the system also increase the heat transfer rate inside the PV collector.

- Similar efficiency gains can be achieved by using fewer fin elements and by creating the correct turbulence model compared to the cost of the cooling unit. In addition to the heat transfer surface area and air velocity, it is seen that the fin arrangement is an important parameter in the heat transfer rate.

- It can be concluded that with better designed fin arrangements, the required fan speed could be lowered for any number of fins or similar results could be obtained with fewer fins. On the other hand, since the power required by 
the PV-powered fan will also decrease with fewer fins and at lower air velocities, the total efficiency obtained from the PV system will also increase.

\section{FUTURE SCOPE}

- The total efficiency of the PV collector dependent of the thermal contact of area of the fin.so the contact area of the fin increases the total efficiency of the PV collector increases.

- And the performance of the PV collector improved by changing the design of the fin. The change in fin will also improve the performance and efficiency of the PV collector.

\section{REFERENCES}

1. Pushpendu Dwivedi, K.Sudhakar "Advanced cooling techniques of P.V. modules: A state of art" Case Studies in Thermal Engineering, Volume 21, October 2020, 100674.

2. Gandhi Mallela, PallaviPaturu, and M. Komaleswarao. "Lift and drag performance of NACA0012 airfoil at various angle of attack using CFD." International journal of mechanical and production engineering research and development 8.3 (2018).

3. MuhammetKaan YEŞILILYURT, Mansour NASIRİ "Techniques for Enhancing and Maintaining Electrical Efficiency of Photovoltaic Systems" International Journal of New Technology and Research (IJNTR) ISSN:2454-4116, Volume-4, Issue-4, April 2018 Pages 44-53.

4. Reddy, P. Surendra, et al. "Wind load analysis of solar farm using computational fluid dynamics." Int J Mech Prod Eng Res Dev 9.6 (2019): 485-498.

5. AN. Özakın, M. K. Yeşilyurt, and K. Yakut, "Experimental Investigation of Thermal Performance of Photovoltaic Thermal (PVT) Systems," International Journal of Engineering Research \& Science (IJOER), vol. 3, no. 12, pp. 23-27, 2017.

6. Paturu, Pallavi, et al. "Numerical Analysis of Flow Over NACA0012 at Fixed Mach Number Using Computational Fluid Dynamics." International journal of mechanical and production engineering research and development 7.6 (2017): 213-222.

7. S. Dubey, J. N. Sarvaiya, and B. Seshadri, "Temperature Dependent Photovoltaic (PV) Efficiency and Its Effect on PV Production in the World - A Review," Energy Procedia, vol. 33, pp. 311-321, 2013.

8. Mansour NasiriKhalaji, MuhammetKaanYeşilyurt "Techniques for Enhancing and Maintaining Electrical Efficiency of Photovoltaic Systems" April 2018.

9. Ziyad S Haidar, Jamel Orfi "Experimental Investigation of Evaporative Cooling for Enhancing Photovoltaic Panels Efficiency" Results in Physics 11 • October 2018.

10. Aarti Kane, Vishal Verma "Optimization of thermoelectric cooling technology for an active cooling of photovoltaic panel" Renewable and Sustainable Energy Reviews 75 • November 2016.

11. Z. A. Haidar, J. Orfi, and Öztop, H. F., Kaneesamkandi, Z., "Cooling of Solar Pv Panels Using Evaporative Cooling," Journal of Thermal Engineering, vol. 2, no. 5, 2016.

12. Sarjito, WaluyoAdiSiswanto, AgusJamaldi, and Yufeng Yao. "Selecting nozzle arrangement of a chimney tower to reduce temperature and to increase entrainment mass flow." International Journal of Mechanical and Production Engineering Research and Development 8.6 (2018): 81-90.

13. RachidMaouedj, MiloudBenmedjahed "Improving photovoltaic panel efficiency using water cooling" April 2020

14. Kumar, Nitesh, et al. "Numerical investigation of blood flow through abdominal Aneurysms." International Journal of Mechanical and Production Engineering Research and Development 9.5 (2019): 733-742..

15. GökhanÖmeroğlu "Experimental and computational fluid dynamics analysis of a photovoltaic/thermal system with active cooling using aluminum fins" Journal of Photonics for Energy 7(04):1 • November 2017.

16. Pittala, Suresh, and T. Diriba. "Computational Fluid Dynamics Analysis of Impeller Design For A Pump." International Journal of Mechanical Engineering (IJME) 5.4. 